Georgetown University Institutional Repository http://www.library.georgetown.edu/digitalgeorgetown

The author made this article openly available online. Please tell us how this access affects you. Your story matters.

Heelan, P. "Heisenberg and Radical Theoretic Change," Zeitschrift für allgemeine Wissenschaftstheorie, 6 (1975), 113-138.

Collection Permanent Link: http://hdl.handle.net/10822/550875

(C) 1975 Franz Steiner Verlag $\mathrm{GmbH}$

This material is made available online with the permission of the author, and in accordance with publisher policies. No further reproduction or distribution of this copy is permitted by electronic transmission or any other means. 


\title{
Heisenberg and radical theoretic change
}

\author{
PATRICK A. HEELAN \\ Georgetown University \\ Washington, DC 20057
}

\begin{abstract}
Heisenberg, in constructing quantum mechanics, explicitly followed certain principles exemplified, as he believed, in Einstein's construction of the special theory of relativity which for him was the paradigm for radical theoretic change in physics. These were the principles of (i) scientific realism, (ii) stability of background knowledge, (iii) E-observability, (iv) contextual re-interpretation, (v) pragmatic continuity, (vi) model continuity, simplicity. Fifty years later, in retrospect, Heisenberg added the following two: a principle of non-proliferation of competing theories - scientific revolutions are not a legitimate goal of physics and (ix) a principle of tenacity - existing theories are to be conserved as far as possible. The conservative as well as the revolutionary potential of these principles is then discussed. A more penetrating philosophical criticism of these principles is postponed.
\end{abstract}


Heisenberg and radical theoretic change

\author{
PATRICK A. HEELAN \\ Georgetown University \\ Washington, DC 20057
}

\title{
Introduction
}

I wish to address myself to the question of rational research-guiding principles during episodes of radical theoretic change. I assume that radical theoretic changes occur in science and that the discovery of relativity (special and general) and of quantum mechanics were instancers of such changes. I do not wish, however, to endorse any particular account or explanation of those changes; rather my purpose is to attempt to criticize and improve the accounts and explanations that are at present available. I shall occasionally use, when convenient, terminology borrowed from contemporary literature on the topic of growth and development of scientific knowledge, as, for example, Kuhn's distinction between 'revolutionary' and 'normal' science, or Radnitzky's 'territory', 'internal' or 'external steering field', etc., but in so doing I wish merely to refer to certain identifiable phenomena (to the extent that this can be done) without endorsing the theories of which these terms may also be a part.

Among those who admit in some sense the existence of radical theoretic change in science are, on the one hand, those who adhere to Reichenbach's distinction between the context of discovery and the context of justification: rational principles, they would say, apply only to the latter. Among this group, for example, are most of the adherents of the Received View ${ }^{\mathbf{1}}$ in the philosophy of science ${ }^{1}$, as well as K. Popper, T. S. Kuhn, P.Feyerabend, I. Lakatos and pragmatists and historicists in general ${ }^{2}$. All would deny that the process of discovery of radically new theories is something to which rational researchguiding principles apply: the facts and circumstances of discovery are, they would say, of interest only to psychologists, historians and sociologists. On the other hand, there are those adherents of the Received View, like I. Scheffler, and many historically-oriented philosophers of science, like D. Shapere, R. N. Hanson, as well as praxiologists of science, notably G. Radnitzky, and systems theorists of research, such as $\mathrm{H}$. Tornebohm and E. Laszlo, ${ }^{3}$ who affirm the existence of rational research-guiding principles for growth in knowledge, even for instances of radical theoretic change.

Using Kuhn's ${ }^{3 a}$ distinction between 'normal' and 'revolutionary' science, there exists, he says, for normal science a disciplinary matrix and exemplar instances of research that together control the growth of and impose their form of rationality on the process and product of change: this paradigm is precisely a mode for the progressive and rational acquisition of (antecedently categorized) knowledge. For revolutionary science, however, defined as radical theoretic Postprint: "Heisenberg and Radical Theoretic Change," Zeitschrift für allgemeine Wissenschaftstheorie, 6 (1975), 113-138. 
change with a resulting change of paradigm, there is the twofold question of (a) rationality (or lawfulness) of the process of change and, (b) the rationality of (or warrant for) the product of change. The following are the three possibilities: (i) there are no rules for (a), only for (b); (ii) there are some necessary, perhaps sufficient, principles for (a), but not sufficient for (b) ; (iii) there are a sufficient set for (a) which are also sufficient for (b).

The case history that will be studied in this paper is that of Heisenberg's discovery of quantum mechanics, which it will be assumed is an instance of radical theoretic change in physics. It is clear from the record that Heisenberg sought guidance in the model of theoretic change brought about in physics by Einstein, also assumed by me to be an instance of radical change. It is clear that for him the rational warrant of quantum mechanics - the product of change included as necessary conditions, fulfillment of the principles of the model. It is arguable, however, whether the principles of the model were or were not in his view sufficient to guarantee of themselves the acceptability of the product of change. The fact is that Heisenberg at the time he was fashioning quantum mechanics was led by certain research-guiding principles which we shall attempt to formulate below. To this list will be added certain others which he came to affirm in the retrospect of fifty years later but which were not part — as far as one can judge of the original set. It will be held by some that these facts are of interest only to psychologists and others, but not to methodologists and philosophers of science. Since it is my claim, however, that they are indeed of interest to the philosopher and methodologists of science, I shall attempt in another paper to study these principles critically and show to what extent they may possibly lay claim to universal validity for radical theoretic change in science.

\section{Historical Context}

In the years just preceding 1925, physics was in a state of crisis. There were major significant unresolved anomalies, which strongly suggested that a breakthrough, when it occurred, would result in radical changes in the edifice of physics. Heisenberg was one of those convinced that a scientific revolution had to take place and, looking for a model of such a revolution, he found one already at hand in Einstein's work on relativity, particularly on special relativity, still at that time the focus of residual controversy. ${ }^{4}$ For example, that none but observables must go into a physical theory, was an insight he derived from Einstein. ${ }^{5}$ Likewise, his strategy of using the formalism of quantum mechanics to reinterpret the kinematical variables instead of accepting their traditional sense from classical physics, was derived from Einstein'. A comparison between relativity and quantum mechanics as they relate to classical physics brings out additional resemblances between the two great scientific revolutions of this century. In this paper, I shall try to formulate the principles for a scientific revolution that Heisenberg read into his study of relativity, and used in the discovery of quantum mechanics.

Let us first focus on the revolutionary strategy used by Einstein. At the turn of the century, the four main theoretical divisions of physics were mechanics, electromagnetics, thermodynamics and gravitational theory. Each theory described a certain kind of system in space and time, and gave mathematical laws for its 
dynamical development. Mechanics dealt with mass particles and continuous ponderable media. Electromagnetics dealt with electric charges, magnetic dipoles and electromagnetic fields. Einstein noted the puzzling fact that mechanical and electromagnetic laws have different space-time properties. Mechanical laws, on the one hand, are covariant ${ }^{7}$ relative to Galilean frames ${ }^{8}$; electromagnetic laws, on the other hand, are covariant relative to Lorentz frames ${ }^{9}$ But a Galilean frame is not usually a Lorentz frame, except in the instances where both coincide with (different coordinatizations of) absolute space and absolute time, the unique objective containers of physical objects and events.

Absolute space and time, however, eluded all experimental attempts to determine their relation to the frames actually used in science and everyday life. They remained hidden. To explain this puzzling phenomenon, two quite different strategies were used, one by Lorentz and Fitzgerald and the other by Einstein. The conservative strategy pro-posed by Lorentz and Fitzgerald was to explain the negative results of these experiments by a universal contraction of rods and a universal dilation of time intervals in inertial frames other than that of absolute space and time. ${ }^{10}$ This enabled the traditional relationships between space, time and mechanics to be maintained. A revolutionary strategy, however, was proposed by Einstein. ${ }^{11}$ It had four parts: (1) he denied reality-status to absolute space and absolute time; (2) in the order of logic (semantics) and meaning, he reinterpreted the state variables (coordinates and momenta) as logically (semantically) relative to members of a unique set of local frames of reference; (3) in the order of the ontology of space and time, he proposed to locate their reality in a unique group structure of local spatio-temporal frames of reference, which group he took to be that of the inhomogeneous Lorentz group; (4) in the order of the ontology of nature, he proposed to locate physical objects, events and structures in and only in the contents of physical theories that were covariant relative to the inhomogeneous Lorentz group. The outcome of these proposals, specifically of (4), was a change in the laws of mechanics.

Einstein's proposal was a revolutionary strategy chiefly for three reasons : it made changes in the laws of mechanics, laws thought to have been established immutably by Newton; it gave a semantical re-interpretation to the basic kinematical variables of mechanics, and it changed the notion of scientific objectivity. Heisenberg later spoke of Einstein's "stroke of wizardry" resolving all difficulties by simply stating that the "apparent time of Lorentz's formulae is actually the real time. ${ }^{\mathbf{1 2}}$ The revision of the ontology of the relativistic domain was itself only the consequence of a process of theory change that incorporated, and presumably was intended to incorporate, the principles which give warrant to the process and hence to the product of change. Let me try to formulate these principles - principles for the rational revolutionary development of physics as Heisenberg saw them exemplified in the relativity model of radical theoretical change.

The terminus a quo is classical physics. Let $\mathrm{L}_{\mathrm{N}}$ be the language in which is embodied the descriptive ontology of classical mechanics. Fortunately, $\mathrm{L}_{\mathrm{N}}$ is a formal language : its basic entities and predicates are clearly designated in its mathematical form and their mutual relationships are implicitly defined through the mathematical equations of motion.

Postprint: "Heisenberg and Radical Theoretic Change," Zeitschrift für allgemeine Wissenschaftstheorie, 6 (1975), 113-138. 
The ontology of classical mechanics is what Heisenberg called "the ontology of materialism" ${ }^{13 .}$ This is the ontology of objects that possess, he says, a special kind of objectivity ${ }^{\mathbf{1 4}}$, independence of the conditions under which they come to be known by particular observers ${ }^{15}$. Let me call these objectifiable objects". ${ }^{16}$ The physical systems of classical physics - localized exactly in absolute Euclidean 3space independently of all observers - are paradigm cases of objectifiable objects.

Although the state variables of a classical system are defined with respect to absolute space and time, local inertial coordinates relative, say, to a laboratory, are as good, since they too satisfy the dynamical equations. A local inertial frame, unlike absolute space, is recognizable; it is generally embodied concretely in the environment surrounding the object. This environment, like the laboratory, is the physical context with respect to which the relative state variables are defined. For Einstein, it was sufficient that a relative state variable referred notionally to the physical context which concretely embodied an inertial frame of reference. For Heisenberg, the relationship between object and frame of reference had to be real, founded on a measuring process, which is a special kind of interaction that leaves a macroscopic trace on a measuring instrument. ${ }^{17}$

Since local environments embody inertial frames, it becomes important to learn to categorize them as similar or dissimilar for the purposes of estimating relative state variables. Do we need descriptive frameworks other than $\mathrm{L}_{\mathrm{N}}$ for this purpose? At first sight, yes ! since what has to be determined are precisely the conditions under which $\mathrm{L}_{\mathrm{N}}$ is applicable. Let us call the knowledge systems required for this task, stable background knowledge relative to the applicability of $\mathrm{L}_{\mathrm{N}}$. But might not $\mathrm{L}_{\mathrm{N}}$ be part of its own stable background knowledge system ? Paradoxically, the answer is yes!, provided $\mathrm{L}_{\mathrm{N}}$ can serve as an observational language, since an observational language - one used directly and immediately of experience - does not need the mediation of any other language for its valid use. But is $\mathrm{L}_{\mathrm{N}}$ an observation language? Einstein and Heisenberg, following the Kantian (or Neo-Kantian) tradition, took the position that $\mathrm{L}_{\mathrm{N}}$ is both in fact and in principle an unmediated observational language, a refinement of natural language and the one and only language appropriate for the experience of all everyday physical objects. ${ }^{18}$

I should like to compare this with another view, the pragmatic theory of observation which holds that, through use and familiarity, a theoretical language framework like $\mathrm{L}_{\mathrm{N}}$ can become appropriated for observational use ${ }^{\mathbf{1 9}}$. The reasons in favor of some version of the pragmatic theory of observation are based on the analysis of the subject-object cut for embodied observers like human perceivers. ${ }^{20}$ To point up the philosophical problem of a stable background observational language, let me consider the paradigm case of the transformation in everyday language effected by the Copemican revolution.

The ontological commitments of pre-Copemican man were carried in his observational language which I shall call, Aristotelian language, $\mathrm{L}_{\mathrm{A}}$. In $\mathrm{L}_{\mathrm{A}}$, the observer takes the soil on which he stands as fixed and immobile. We find echoes of this pre-Copernican frame in such common expressions as, "The sun rises in the moming and sets in the evening". In $\mathrm{L}_{\mathrm{A}}$, the sun's motion is real. 
If asked to interpret this expression today, we merely say that we are using a conventional phrase to mean that the sun merely appears to rise and set. The sun's motion, real in the earth-centered frame, $\mathrm{L}_{\mathrm{A}}$, becomes merely an appearance of motion in the heliocentric frame of $\mathrm{L}_{\mathrm{N}}$ in which the sun is the fixed and immobile center of the solar system. A radical change in the ontological commitments of everyday language relative to motion followed the replacement of $\mathrm{L}_{\mathrm{A}}$ by $\mathrm{L}_{\mathrm{N}}$ as the language of everyday observation. Was this the conversion of $\mathrm{L}_{\mathrm{N}}$ from a theoretical to an observational language? Or was it the discovery of the uniquely correct observational language for perceptual experience? My view is the former, Heisenberg's the latter.

Whence comes the warrant for the ontological commitments of language? Is it a matter merely of taste or convention, as some would hold? Or is it the product merely of historical and sociological factors, authorities and the like? We are concerned not with such reasons, but with possible philosophical grounds for rejecting the Aristotelian usage and adopting in its place the modern usage incorporating the Copernican viewpoint. Einstein believed that philosophical principles were involved in the choice of an ontology. Ontological assertions about Nature, he held, are not validly made in any pre-theoretical language, but only within the theoretical (mathematically explanatory) linguistic framework of a physical theory ${ }^{21}$ Of the variety of conventionally sanctioned frame-works actually used to describe the world, only one in his view described what was really the case : that was the scientific frame. The Aristotelian linguistic frame, or what Wilfred Sellars calls ${ }^{22}$, the "manifest image of the world", spoke for him; as for Sellars, merely of a phenomenal realm that was destined to give way to the reality to be revealed by the correct theoretical description. Heisenberg's view was more complex: from Pythagoras, Plato and Democritus came the impulse to explain immediate and direct perceptual qualities by the geometrical and other mathematical properties of fundamental non-perceptual entities, atoms and the like: ${ }^{23}$ the history of modern science is the story of the successful growth of a mathematical explanation of nature. Contrasting mathematical methods with perception-theoretic methods (such as, for example Goethe's) he asserts, "the attempt to prove impossible a perception-theoretic understanding... and to prove mathematical analysis the only possible way, appears to me as unwise as the opposite assertion that the understanding of nature can be achieved in a philosophical way without the knowledge of its formal laws"24 Scientific language then though formal, does not replace ordinary language; rather is it to be considered as the "natural extension of ordinary language" 25 . To the mathematical symbols of the theory are given names that refer to experiments or (measurement-) processes describable in ordinary language. Classical physics, moreover, is a precise rendering of the world as given in ordinary perceptual experience, "The words of [our] language represent the concepts of daily life which in the scientific language of physics may be refined to the concepts of classical physics. "26

For Heisenberg then the scientific image of the world is certainly real, but it is not exhaustive of reality - there are, as he asserts, values, the works of the human spirit, religion, none of which enter into physics ${ }^{27}$. But in the philosophy of physical nature, the scientific image has primacy ${ }^{28}$. He applied to Max Planck his description of the perfect scientist, "[his] gaze ... was directed to the still 
distant summit of atomic theory whence it would be possible to discern not only the existence of elementary particles and all the atomic products composed of them, but also in-directly the physical interconnections of the world in general, as a consequence of a simple mathematical structure"29. That was the goal he shared with Einstein and Planck grounded on scientific realism ${ }^{30}$.

\section{Stable Background Knowledge}

For Einstein, ${ }^{31}$ however, as for Heisenberg, there was - despite revolutionary changes in physics a certain unrevisability about $\mathrm{L}_{\mathrm{N}}$, in so far as, they believed, $\mathrm{L}_{\mathrm{N}}$ is in principle a priori to all subsequent theories in physics. ${ }^{32} \mathrm{LN}$ was, in their view, the only correct language in principle for everyday macroscopic non-relativistic phenomena, the phenomena of daily life. Everyday language then, for them, incorporated $\mathrm{L}_{\mathrm{N}}$ immutably for the domain of macroscopic non-relativistic phenomena, such as the instruments and signals that constitute the everyday face of all the phenomena large and small, scientific and non-scientific, ${ }^{33}$ It should be noted that everyday language is neutral to the transposition from $\mathrm{L}_{N}$ to $\mathrm{L}_{R}$ (the language of relativity) in the domain of relativistic phenomena only, not in the realm of everyday phenomena, where $\mathrm{L}_{\mathrm{N}}$ is assured of a permanent place in principle. The reason given for the un revisability of $\mathrm{L}_{\mathrm{N}}$ is the alleged necessity - for the purposes of scientific inquiry - of $\mathrm{L}_{\mathrm{N}}$ to describe the process and results of experimentation.

Heisenberg goes further in specifying the background knowledge for scientific inquiry. As a field of scientific inquiry develops, every phase of the inquiry rests on the stable past accomplishments of the field, particularly on what he calls, Closed Theories, that is, theories closed-off from internal development by reason of the fact that they have achieved axiomatic form. ${ }^{34}$ Such closed theories have a non-empty domain of applicability, but the extent of that domain, he holds, can never be anything but indefinite : future research then cannot falsify a Closed Theory; it can only discover restrictions on its domain. For Heisenberg then, radical theoretic change presupposes a fund of stable background knowledge - observational and theoretical - that comprises the language and concepts of classical physics $\left(\mathrm{L}_{\mathrm{N}}\right)$ and the set of Closed Theories that constitute the existing stage of the permanent achievement of science.

Whatever about the apriori character of $\mathrm{L}_{\mathrm{N}}$, whatever about the value of what he calls Closed Theories, Heisenberg has indeed argued plausibly that all experimentation takes place only on the supposition that there is a fund of stable background knowledge, both pre-theoretical (or observational) and theoretical, that permits the construction of essentially similar pieces of apparatus and the recognition of essentially similar signals. This I call the principle of stable background knowledge.

\section{E-Observability}

A second principle Einstein used at least in the development of the special theory was a principle of observability. Under the influence of Ernst Mach's principle of thought economy, Einstein rejected the existence of absolute space and time because they were in some sense unobservable. In what sense observability counted and why, was never fully and critically formulated by Einstein. He came, moreover, to change his view about observability during the period between special relativity (1905) and general relativity (1915). What is 
relevant to our discussion, however, is what Heisenberg in 1925 thought Einstein meant by observability and how he fashioned a principle of observability derived as he believed from Einstein. This principle I shall call the principle of E-observability ${ }^{34 a}$.

Heisenberg launched his theory of quantum mechanics with the ex-planation that his basic principle was to consider only relations between observable magnitudes ${ }^{35}$. The rhetoric echoed Einstein's of 1905; the message was revolutionary since it seemed to attack the entrenched rationalism of the German academic scene. The principle sounded like the rallying-cry of young inconclastic positivists, "Clean out from physics the remnants of metaphysics, religion and mysticism!" A closer inspection, however, reveals that Heisenberg's basic insight was far less revolutionary than it sounded. Heisenberg had no wish to deny the three hundred years of physics based upon the mathematization of qualities as measured in order to return to a pre-Galilean or Aristotelian physics based upon qualities as sensed. What stimulated Heisenberg's insight was the re-cognition that certain variables, like the intra-atomic electron orbits appearing in the old quantum theory were not mea surable. Energy levels, intra-atomic electrons, spin and a host of other entities are not observable in a positivist sense; but what distinguishes them from the orbits of intra-atomic electron is that they are measurable, and to that extent, they are, what I call, E-observable.

The principle of E-observability can be formulated in the following way: A scientific descriptive language $\mathrm{L}$, to yield true ontological descriptions, must be such that every descriptive predicate in it has observable consequences; that is for every predicate $\mathrm{F}(-)$ in $\mathrm{L}$, there exists some warranted empirical fact, the description of which in L, namely, $\mathrm{S}$ ( - F (a), - ) uses F (a) essentially. (A sentence $\mathrm{F}(\mathrm{a})$ is used essentially in $\mathrm{S}(-, \mathrm{F}(\mathrm{a}),-$ ), if and only if, when $\mathrm{F}(\mathrm{a})$ is replaced by its negative $\sim F(a)$, the truth of $S(-, F(a),-$ implies the falsity of $S(-, \sim F(a),-))$. Such an empirical fact, $\mathrm{S}(-, \mathrm{F}(\mathrm{a}),-$ ) is equivalent to a measurement of $\mathrm{F}(\mathrm{a})$, since it provides an empirical criterion to discriminate between the two cases $\mathrm{F}$ (a) and $\sim \mathrm{F}$ (a) (a kind of yes/no test for $\mathrm{F}$ (a) !) : it is assumed of course that the two facts $\mathrm{S}(-, \mathrm{F}(\mathrm{a}),-)$ and $\mathrm{S}(-,, \sim \mathrm{F}(\mathrm{a}),-)$ have identical conditions except for $\mathrm{F}$ (a) or $\sim \mathrm{F}$ (a).

It is possible to read Heisenberg's philosophical development as the passage from an early empiricist phase to a later rationalist, even idealist, phase. ${ }^{36}$ Within this perspective, one would point out in his earlier writings, the blurring of the distinction between the observable signifier of the scientific fact, e.g., the track on the photographic plate, and the scientific fact signified by (and made observable through) the signifier, e.g., the electrons that made the tracks. The signifier (taken as an in-dependent object) is a fact in the everyday world: the signified object is a scientific fact for which the predicates of the everyday world are - generally at least - neither applicable nor appropriate; except in so far as everyday language is reductively scientific, as would be the case if it were normed, as Heisenberg thought it was, by the language of classical physics ${ }^{37}$.

It is possible, however, to put a different construction on Heisenberg's writings and to read these as gradually expressing recognition of the fact that the revolutionary empiricist language he had borrowed from Mach, Bohr and the early Einstein, did not express the true complexity of his position, since it left out something of which he was always at least dimly aware, namely, the theory-laden character of observables. In this paper, I am adopting the latter perspective which I now believe to be preferable. In confirmation, we have 
Heisenberg's report (admittedly written many years later!) of a conversation with Einstein in Berlin in the spring of 1926 about the role of observables in physics. The impression Heisenberg gives us is that Einstein's strong dislike of what he heard was occasioned by the vocabulary Heisenberg used with its echoes of positivism, rather than by the substance of what was said with Einstein seemingly failed to grasp ${ }^{38}$. "It is the theory which tells us what we can observe", Einstein peremptorily told a bewildered Heisenberg, articulating what Heisenberg always meant but perhaps has not been able to express ${ }^{39}$.

The principle of E-observability so expressed makes the observable character of a predicate a necessary but not, however, a sufficient condition of the descriptive status of a language. Consequently, the principle does not prove theories but refutes conjectures. Since all the predicates of a well-formulated theory constitute an implicit meaning circle, the conjecture that is refuted is probably not the existence of a single unobserved predicate, but most likely the acceptability of the theory as a whole. ${ }^{40}$. So the unobservability of electron orbits, led Heisenberg to attempt to change the very substance of the theory by re-defining the very meaning of state variables. Through a change in the mathematical form of the theory and then - as we shall see in the next section - in the semantic re-interpretation of the theoretical symbols. The same implicit meaning circle also implies that for him there is no occurrence of a fact or observation of a predicate that does not suppose at least the tentative acceptance of the linguistic framework of the theory ${ }^{41}$. Hence, the kind of observation-event that warrants a predicate as observable is for him a posttheoretical fact, not a pre-theoretical fact. Despite the apparent disagreement expressed by Einstein in his conversation with Heisenberg already mentioned, neither of them supported the view characteristic of empiricism that a scientific theory represents either a mere generalization of pre-theoretical experience or a second- (or third-) level systematization removed from ontological description. ${ }^{42}$

\section{Contextual Re-interpretation of the Formalism}

About the failure of every attempt to observe absolute motion, Heisenberg wrote, "Here Einstein took a hand, and with one stroke of wizardry resolved all the difficulties. He assumed that the bodies really do contract in the direction of motion, and that the apparent time of Lorentz's formulae is actually the true time and that these formulae therefore convey a new understanding of space and time themselves. He thereby created the basis of the theory of relativity. ${ }^{43}$. The Einsteinian revolution that followed was a revolution in descriptive ontology introduced by a transformation of linguistic usage ${ }^{44}$ The transformation of linguistic usage was the result of a semantical reinterpretation of the kinematical variables making them contextually dependent on a unique class of observers (instrumental reference frames), those that constitute the manifold of inhomogeneous Lorentz group. This transformation was effected by what I call the principle of contextual reinterpretation of the formalism. For Einstein, contextualization was merely notional; it meant no more than a conceptual relativity to members of a class of observer-frames. For Heisenberg, however, contextualization was real ! it made the measurement process itself the basis for a real relativity between the quantum mechanical observable and the class of its observerframes. ${ }^{45}$. 


\section{Pragmatic Continuity}

Two other principles of rational development are involved in what is called Korrespondenzdenken, that is, in the belief that there is a smooth passage between classical physics, and relativity and quantum mechanics. It is supposed that if $L_{R}$ is a rational development or extension of $L_{N}$, then the domain of applicability (Radnitzky's territory ${ }^{\mathbf{4 6}}$ ) $\mathrm{D}_{\mathrm{R}}$ of $\mathrm{L}_{\mathrm{R}}$ contains the domain of applicability $D_{N}$ of $L_{N}$; that is, $D_{R}>D_{N}\left(D_{R}\right.$ is greater in extension than $\left.D_{N}\right)$.

What does applicability mean? When is a theory applicable? What can be derived about the relative power of two theories when $\mathrm{D}_{\mathrm{R}}>\mathrm{D}_{\mathrm{N}}$, and what can be said about the relation between the theoretical concepts of $L_{B}$ and $L_{N}$ if both theories are applicable in a common domain?

A scientific theory is applicable over a domain D, if and only if it fulfills the systematic and predictive goals of science for that domain. The systematic goals of science provide objective understanding of the domain: the predictive goals permit control and manipulation of the events and processes of the domain $^{\mathbf{4 7}}$. But are the two goals different? Is objective understanding different from the power to manipulate predict and control? There are some who say that for the sciences, understanding is none other than the know-how to predict and control. No so for Einstein and Heisenberg: for them, scientific understanding is oriented towards ontology, the way things are and act; and this is intimately involved with mathematical representations of nature - the scientific image. Prediction and control may or may not follow depending on the subject matter: for satellites and space stations, yes! for general cosmology, certainly, no !

If two theories such as $\mathrm{L}_{\mathrm{N}}$ and $\mathrm{L}_{\mathrm{B}}$ are applicable to a common domain such as $\mathrm{D}_{\mathrm{N}}$, both provide understanding and to the extent possible,

prediction and control over the events and processes of $\mathrm{D}_{\mathrm{N}}$. Leaving out of account the question of what constitutes understanding, or whether or under what conditions $\mathrm{L}_{\mathrm{N}}$ and $\mathrm{L}_{\mathrm{R}}$ could provide a common understandingover $\mathrm{D}_{\mathrm{N}}$, we can speak about the predictive power of the two theories in their common domain. If $\mathrm{L}_{\mathrm{R}}$ is to be the rational extension of $\mathrm{L}_{\mathrm{N}}$, then at least it must be true that to every problem of prediction and control in the domain $\mathrm{D}_{\mathrm{N}}$ that $\mathrm{L}_{\mathrm{N}}$ solves correctly (to a specified degree of accuracy), LR, must also provide a correct solution (to the same specified degree of accuracy). That condition, I call, the principle of pragmatic continuity: It represents one aspect of Korrespondenzdenken, and it purports to be a principle of rational growth of knowledge. ${ }^{48}$

\section{Model Continuity}

If in addition to pragmatic continuity, we add the condition that $\mathrm{L}_{\mathrm{E}}$ is a rational extension of $\mathrm{L}_{\mathrm{N}}$, then something more is said - that the understanding (as well as predictive control) given by $L_{R}$ over $D_{N}$ is the same as that given by $\mathrm{L}_{\mathrm{N}}$ over $\mathrm{D}_{\mathrm{N}}$. Since scientific understanding for Einstein and Heisenberg is essentially of the implicit correlations between scientific terms given by the mathematical equations of a theory ${ }^{49}$, if the understandings conveyed by $L_{R}$ and $\mathrm{L}_{\mathrm{N}}$ are to be the same, they must have formally isomorphic mathematical models over the domain $D_{N}$ (to the degree of accuracy that is significant) ${ }^{\mathbf{5 0}}$. Model Postprint: "Heisenberg and Radical Theoretic Change," Zeitschrift für allgemeine Wissenschaftstheorie, 6 (1975), 113-138. 
continuity is, for Einstein and Heisenberg, a guarantee of meaning-invariance over theory change. By the mathematical model of a theory, I mean the set of symbols, syntactical rules of formation, postulates and equations that, when given a particular semantical interpretation, becomes a scientific language over the domain in question.

Applying this condition of model continuity to $\mathrm{L}_{\mathrm{a}}$ and $\mathrm{L}_{\mathrm{N}}$, it follows with Einstein that $L_{R}$ is a rational development and extension of $L_{N}$ only if, in the limiting case of the non-relativistic domain (using an appropriate limiting process, e.g., $\mathrm{v} / \mathrm{c} \rightarrow 0$ ), $\mathrm{L}_{\mathrm{a}}$ and $\mathrm{L}_{\mathrm{N}}$ present a formal isomorphism of mathematical theoretical structure ; that is, when one passes to the limiting case, both kinematical and dynamical variables in $\mathrm{L}_{\mathrm{R}}$ must have the same theoretical relationships to one another that they have to $\mathrm{L}_{\mathrm{N}}{ }^{\mathbf{5 1}}$. This is the syntactic aspect of Korrespondenzdenken. I shall call this the principle of model continuity. It too purports to be a principle of rational growth of knowledge ${ }^{\mathbf{5 2}}$.

\section{Simplicity and Beauty}

The list of principles of rational theory change would be incomplete without mention of the properties of simplicity and beauty. It is a common view of scientists shared by both Einstein ${ }^{53}$ and Heisenberg, ${ }^{54}$ that all theories are simple and beautiful that truly mirror Nature. But what is simplicity? How do we judge the beauty of a scientific theory? To formulate criteria for these is as difficult as it is to say why one art object hits it off and another does not. Einstein intended one thing by these terms; Heisenberg apparently intended something else, and Schroedinger something different again. All we can say with certainty is that each claimed to be able to recognize simplicity and beauty and that nevertheless they disagreed profoundly in their concrete judgments about particular theories; for example, about Heisenberg's Matrix Mechanics. However, the fact of disagreement does not imply that criteria do not exist, only that there are different sensibilities, different "esthetic" styles in science as in art. Criteria of this kind belong to the transcendental (or non-objective) conditions of possibility of theoretical scientific rationality. Whether or not these conditions are fixed is a matter for dispute. Nevertheless, theories, old and new, are subject to a principle of simplicity (of objective form) on account of which they are seen to possess the kind of beauty that is the splendor of scientific truth and a manifest of its presence.

Heisenberg had then before him in 1925; explicitly or at least implicitly, seven principles which he believed radical theoretic change should obey ${ }^{55}$ the principles of (i) scientific realism; (ii) stability of background knowledge; (iii) E-observability; (iv) contextual re-interpretation; (v) pragmatic continuity; (vi) model continuity; (vii) simplicity.

In his latest book written about fifty years after the great achievement of quantum mechanics ${ }^{\mathbf{5 6}}$ Heisenberg addressed himself in a lecture entitled "The End of Physics?" to the question of revolutionary change in physics. "How does one make a [scientific] revolution ?" he asks. "By trying to change as little as possible", he replies. ${ }^{57}$ Revolutions have occurred, he admits, and these have altered the edifice of physics down to its foundations, but "never in its history has there been a desire for any radical reconstruction of the edifice of physics", he asserts, "it is precisely the wish to change as little as possible which demonstrates that the introduction of novelty is a matter of being Postprint: "Heisenberg and Radical Theoretic Change," Zeitschrift für allgemeine Wissenschaftstheorie, 6 (1975), 113-138. 
compelled ... by nature itself and not by human authorities of any kind". To demand a radical revision of physics would "run the risk of wanting uncritically to change things even where change is made impossible for all time by the laws of nature".

What Heisenberg is saying in summary adds to the original set of principles the following : (viii) a scientific revolution, though affecting a particular social group — the scientific community - has never been the express goal of that group, nor ought it ever to become an express goal (principle of non-proliferation of competing theories), instead, (ix) scientists ought to direct their efforts towards resolving residual problems while conserving existing theories as far as possible (principle of tenacity) ${ }^{58}$; for only in this way will the mistake be avoided of trying to make changes in theories that are unrevisable.

Within the context of the two extremes of theory-monism and theorypluralism, Heisenberg is today certainly not to be counted among, the latter ${ }^{59}$. Neither is he, however a monist-reductionist. He believes physics is cumulative and that revolutions are essentially conservative ending in the unification by transformation of the established domains of physics subject to the principles of continuity contained in the list enuntiated above $\mathrm{e}^{\mathbf{6 0}}$.

Age tends to make people more conservative and gradualist in their views, and Heisenberg is no exception. It is therefore instructive to learn that his present attitude towards continuity and change does not negate any of the former principles which would still apply, we would suppose, in the future to any conceivable radical theoretic change. He would now however, explicitly enjoin physicists against seeking deliberately to bring about radical change (viii and ix). Nevertheless, the original seven principles contain important conservative and gradualist elements: for example, the use of an accredited model even in change, and of certain continuity principles, viz., (ii), (v) and (vi). Principle (i) is a statement of scientific realism from which he has never moved - despite his acceptance of complementarity. The other three principles contain revolutionary potential.

These last three potentially revolutionary principles can be expressed as research-guiding injunctions: (a) Test for E-observational adequacy (principle iii) ! (b) Preserve continuity of mathematical formalism but be open to the need for semantical re-interpretation of the formalism (Principle iv) ! (c) Look for theories that unify and simplify the existing multiplicity of theories (Principle vii)!

All three of these injunctions have a certain mutual independence: the thrust for observational adequacy, the search for a better, perhaps revolutionary semantical interpretation of the formalism and, the desire for theoretical unity and simplicity in science touch on different and independent kinds of research endeavor. The testing for observational adequacy enjoined by (a) used experimental methods based on the accepted paradigm for the theory. The search for better semantical interpretation of a formalism enjoined by (b) uses a kind of critical eidetic reflection on the functioning of the paradigm in order to correct the interpretation of the model or to open it up to new possibilities linked to the same mathematical model by giving the terms and equations of the model new semantical meanings. ${ }^{61}$ Finally the search for theoretical unity and simplicity enjoined Postprint: "Heisenberg and Radical Theoretic Change," Zeitschrift für allgemeine Wissenschaftstheorie, 6 (1975), 113-138. 
by (c) is a work principally for creative mathematical inventiveness and involves methods different again both from experimental methods and from critical eidetic reflection.

For the early Heisenberg, E-observational adequacy was the primary research-directive that led him to quantum mechanics. Despite the principles of continuity more talked about than evident in quantum mechanics, the first impression his contemporaries got of his version of quantum mechanics was of a theory that contradicted the central principles of continuity and causality that constituted the intelligible core of all science to that date. Einstein, Planck and others were quite unable to accept the new bewildering perspective that was envisioned. Schrödinger was revolted by $\mathrm{it}^{\mathbf{2}}$. Such changes as quantum mechanics proposed affected not merely the content of physics but the very notion of science itself. Heisenberg may well now defend in retrospect the claim that after all "he changed as little as possible", but it makes about as much sense of the quantum mechanical revolution to say that its instigator tried to change as little as possible, as for a surgeon to console a patient whose leg he had amputated, by saying that he made as few incisions as possible in the circumstances.

The revolutionary theoretical form of quantum mechanics made it necessary to find an adequate acceptable semantical interpretation of the new formalism, Since the new formalism was to be continuous with the old (principle of model continuity) the semantical interpretation of the new formalism would possibly effect retroactively a re-interpretation of the old. Heisenberg believed that quantum mechanics did in fact revolutionize the sense of the kinematical variables by contextuatizing them with respect to processes of measurement ${ }^{\mathbf{6 3}}$. To these new (or newly interpreted) variables, following the principle of scientific realism, he attributed descriptive force. Bohr, however, differed from Heisenberg ${ }^{\mathbf{6 4}}$, opposing both the realist sense and the semantical significance given by him to the kinematical variables. Instead he chose what he called the "complementarity" of particle and wave "pictures", these were not in his view true models of atomic phenomena, but only complementary "pictures" of how these phenomena appeared when interacting with macroscopic experimental $\operatorname{contexts}^{65}$, and guided our use of classical language about quantum phenomena. The semantical sense of the classical variables was preserved at the expense of blurring the distinction between signifier and signified. Heisenberg's capitulation to the philosophy (or semantics) of complementarity in March, $1927^{66}$ quelled dispute between the two, but it did not solve the underlying problem ${ }^{67}$. We are left to conclude that the acceptance of complementarity implied Heisenberg's temporary abandonment of the principle of contextual reinterpretation dominant in his early view ${ }^{68}$. The evidence shows that he did not reject the principle, but once he subscribed to the philosophy (or semantics) of complementarity it was difficult to re-instate its claims systematically in quantum mechanics. Since 1925, we have seldom seen the explicit use of critical eidetic methods in physics - attempts by critical eidetic reflection to correct the existing use or interpretation of the mathematical formalism of a theory; physics may be the poorer for lack of such a tool. However, though little in evidence, it is still not forgotten among those who share a scientific realism, especially if this has a strong conceptualist component as it has in Heisenberg and Einstein ${ }^{\mathbf{9}}$.

The main thrust of Heisenberg's research today is guided by the principle of simplicity: it is directed towards the unification and simplification of the existing theoretical divisions of physics in one universal matter equation, that would Postprint: "Heisenberg and Radical Theoretic Change," Zeitschrift für allgemeine Wissenschaftstheorie, 6 (1975), 113-138. 
exhibit all the symmetries of nature and from which would be derived as limiting cases all the existing "closed theories" of physics ${ }^{\mathbf{7 0}}$. Principles \{viii) and (ix) follow from his belief in the cumulative character of physics and in the essential unrevisability of closed theories - closed-off, that is from internal development and complete in their axiomatic form. Heisenberg's conservatism today envisages only what we might call, echoing his own metaphor, the "central edifice" of physics to which, he believes, quantum theory belongs. Future developments in physics, he asserts, will lie in building connections to other disciplines, for example, to chemistry and biology ${ }^{71}$. But the central edifice is nearly complete and to touch it is to risk "wanting uncritically to change things even where change is made impossible for all time by the laws of nature" 72 .

I shall take up the critique of the research-guiding principles formulated above in another study.

\section{NOTES}

1 The term "Received View", coined by H. Putnam, has gained considerable circulation for the tradition of the philosophy of science inspired by the Vienna Circle and Reichenbach's Berlin School. For an excellent summary of criticisms of the Received View and for the existing available alternatives, see the introduction by F. Suppe, in Suppe (ed.) (1974), pp. 3-243.

2. Popper (1972); Kuhn(1962); Lakatos \& Musgrave (1970); Lakatos (1967); Feyerabend (1965) \& (1970).

3 An excellent bibliography of the mentioned authors is contained in Suppe (ed.), (1974) and in a review article by KIsiel and Johnson (1974).

3a. Kuhn (1962).

4.Published and unpublished sources are used in this study. The unpublished sources are in the Archive for the History of Quantum Physics (hereafter referred to as AHQP) compiled and maintained by a Joint Committee of the American Physical Society and the American Philosophical Society, Philadelphia, on the History of Theoretical Physics in the Twentieth Century. The Archive is deposited, in original or duplicate form, at the Library of the American Philosophical Society, Philadelphia, at the Bancroft Library of the University 'of California, Berkeley, at the Niels Bohr Library, American Institute of Physics, New York, and at the Universitets Institut for Teoretisk Fysik, Copenhagen, Denmark. The Archive contains documents on the history of quantum physics and taped interviews conducted by T. S. Kuhn, J. L. Heilbron and others with Heisenberg, Niels Bohr and other quantum physicists. All the interviews cited or referred to were with T. S. Kuhn. Reference and citation will be by date of interview. The writer was enabled to consult this material by permission of the Joint Committee referred to above through the courtesy of Dr. Charles Weiner, formerly Director of the Center far the History and Philosoph $^{\mathrm{y}}$ of Physics, a division of the AIP, New York, and Mrs Joan Warnow, formerly Acting Director of the Center. Permission to quote from the unpublished material was kindly given by Professor Werner Heisenberg and the Joint Committee. The principal published sources for the biographical material are W. Heisenberg are listed in the references.

5.AHQP, 15 February, 1963: Heisenberg said that the importance of observables in physics came to him from relativity, reflecting how Einstein converted "apparent time"

Postprint: "Heisenberg and Radical Theoretic Change," Zeitschrift für allgemeine Wissenschaftstheorie, 6 (1975), 113-138. 
into "real time". This turning of the picture by saying that the real things are those which you observe and everything else is nothing, was, he asserts, in the minds of the people at Gottingen at that time.

6. AHQP, 25 February 1963: Heisenberg said about the discovery of the Uncertainty Principle (1927) "I tried to say what space meant and what velocity meant and so on. I just tried to turn around the question according to the example of Einstein. You know Einstein just reversed the question by saying 'We do not ask how we describe nature by mathematical structures, but we say that nature always makes so that the mathematical scheme can be fitted to it. That is, you find in nature only situations which can be described by means of the Lorentz transformation. Therefore, I just suggested to myself "Well! is it not so that I can only find in nature situations which can be described by quantum mechanics?' Then I asked 'Well! what are these situations which you can define'. Then I found very soon that these are the situations in which there was this Uncertainty Relation between $\mathrm{p}$ and q".

7. Equations are covariant relative to a certain. group of transformations if they are form-invariant with respect to transformations of the group. For a study of the covariances of Newtonian and relativistic physics, see Strauss (1968).

8.The Galilean transformation group comprises (i) spatial and temporal displacements of the form: $x_{i} \rightarrow x_{i}^{\prime}=x_{i}+a_{i}(i=1,2,3), t \rightarrow . t^{\prime}=t+t_{0}$ (ii) threedimensional spatial orthogonal rotations of the form $x_{i} \rightarrow x i=c_{i j} x_{j}(i=1,2$, 3: the dummy index is summed); (iii) uniform motions in a straight line: $\mathrm{x}_{\mathrm{i}} \rightarrow \mathrm{xi}=\mathrm{x}_{\mathrm{i}}+\mathrm{v}_{\mathrm{i}} \mathrm{t}, \mathrm{t} \rightarrow \mathrm{t}^{\prime}$ $=\mathrm{t}$. Every transformation of the spatial or temporal frame can be regarded either passively or actively, see Wigner (1954). I am concerned with the passive interpretation of space-time transformations.

9. The inhomogeneious Lorentz or Poincare group comprises (i) spacetime displacements of the form, $x_{i} \rightarrow x^{\prime}{ }_{i}=x_{i}+a_{i}\left(i=1,2,3\right.$, 4: where $x_{4}$ is the time coordinate) ; (ii) three-dimensional spatial orthogonal rotations; (iii) four-dimensional space-time orthogonal rotations, i.e., real linear transformation which leave invariant the squared space-time interval

$$
\left(a_{1}-b_{1}\right)^{2}+\left(a_{2}-b_{2}\right)^{2}+\left(a_{3}-b_{3}\right)^{2}
$$

separating two events whose space-time coordinates are $\left(a_{11}, a_{2}, a_{3}, a_{4}\right)$ and $\left(b_{1}, b_{2}, b_{3}\right.$, $b_{4}$ ). These last transformations relate two space-time frames of such a kind that the spatial part of one is moving with uniform relative velocity in a straight line relative to the spatial part of the other. I am concerned only with the passive form of the transformations.

10 Lorentz (1904).

11. Einstein (1905) on the special theory of relativity. The language of the paper is more phenomenological than ontological, due perhaps to the influence of Mach's "economy of thought" at this period of Einstein's career. It is clear from his "Autobiographical Notes", published in Schilpp (1949) and other of his writings that Einstein later at least (and certainly before 1916 and general relativity) interpreted the principle of relativity in a realistic way, as asserting something about nature. He also foresaw special relativity giving way to a unified field theory in which there would be no longer any privileged space-time frames or arbitrary constants of nature. Such a transposition, he held, would nevertheless preserve special relativity as a limiting case of the unified theory. Heisenberg's view of Einstein's accomplishment is given in his essay "The Scientific Work of Albert Einstein", AF, pp. 1-7. Heisenberg stressed here the reinterpretation of space-time variables and the consequent change in the ontology of space-time.

12 AF, p. 2. The terms 'appearance' and 'reality' have various usages, and it is not clear which of them Heisenberg intended. Among the usages; for example, (i)

Postprint: "Heisenberg and Radical Theoretic Change," Zeitschrift für allgemeine Wissenschaftstheorie, 6 (1975), 113-138. 
phenomenon (for Kant) as opposed to noumenon, (ii) phenomenon as perceptually given as opposed to the same phenomenon as scientifically explained; (iii) experience described in an unendorsed (or obsolete or uncritical) frame as opposed to experience described in an endorsed (or currently acceptable or critical) frame, etc. According to sense (iii), the length contraction would have been real for Lorentz but, according to Einstein, uncritically so : only from the relativity perspective, would the Lorentz contraction be seen as a mere appearance of what is not really the way it appears. Alternatively, one might use sense (ii) : then the Lorentz contraction is taken as observationally given (truly described) in some way antecedent to the scientific explanation that accrues to it from relativity, See Heelan (1967) for a discussion of reality and appearance.

13. PP, pp $81-2$.

14 The word "object" is ambiguous: it can refer to the entity that is represented or to the representation of that entity by a knower. Objectivity characterizes the former only in virtue of certain features of the latter. Objectivity primarily applies to the objects of knowledge within acts of knowledge.

15 PP, p. 81. "We 'objectivate a statement if we claim that its contents does not depend on the conditions under which it can be verified". Cf. also p. 130.

16. An object comes to be known when two conditions are fulfilled: (1) when it is conceptually categorized (or becomes subject to clear semantical description); (2) when it is recognized by particular observers in particular instances. An objectifiable object then is one which has a two fold independence from observers: (i) a logical (or semantical) independence, and (ii) a real independence. An object is logically (or semantically) independent of observers if its notion does not logically involve any set of observers (whether these be instrumental contexts or human perceivers) or if its descriptive framework does not refer to a class of observers or speakers (instrumental or perceptual). Absolute position and velocity would fulfil this condition (but not relative position and velocity) ; also properties invariant for all observers, such as for example, rest mass or the velocity of light. An object is really independent of observers if it does not depend for the fact of its existence on the activity, for example, of measuring or observing, of any class of observers or speakers. There are two ways in which the fact of existence of an object can come to depend on the activity of an observer: first of all, when the object is the real product of that activity, as, for example, in participant-observer situations in the social sciences, or in the physical sciences, for such properties as are the product of an interaction with a standard set-up that acts simultaneously as a measurement frame. According to one (re-)interpretation, position is the product of a localizing (inter)action with (one of a class of) macroscopic instrumental reference frames; that is, in so far as it is relative, position is according to this (re-)interpretation not a merely notional relation but a real relation founded on the action of the reference frame on it. A second kind of existential dependence on observers arises when the object has existence only in virtue of being recognized by the observer, such as, for example, warm-as-felt, or red-as-sensed, etc.; according to one interpretation of the reduction of the wave packet, quantum mechanical variables also belong to this class. See, for example, London \& Bauer (1939); Wigner (1962);

The physical systems of classical physics are paradigm cases of objectifiable objects. Relativity and quantum mechanics were to change, not merely the kinds of objects admitted to be real, but also the nature of scientific objectivity.

17. See Heelan (1965) - hereafter referred to as QMO — pp. 64-71. In relativity theory, Einstein only went so far as to re-define position as conceptually relative to frames of reference. M. Sachs notes: "it was tacitly assumed that an outside observer will always have at its disposal a set of measuring rods and clocks - to probe the properties of the universe (as closely as he pleases!) ... [but] these investigations did not attempt to

Postprint: "Heisenberg and Radical Theoretic Change," Zeitschrift für allgemeine Wissenschaftstheorie, 6 (1975), 113-138. 
explicitly incorporate the measuring processes", p. 59 in "The Elementarity of Measurement in Relativity", in Sachs (1968). See also. QMO, pp. 73, 76-111.

18. Heisenberg writes: "The concepts of classical physics will remain the basis of any exact and objective science. Because we demand of the results of science that they can be objectively proved (i.e., by measurements registered on suitable apparatus) we are forced to express these results in the language of classical physics ... ; Thus while the law. of classical physics ... appear only as limiting cases of more general and abstract connections the concepts associated with these laws remain an indispensable part of the language of science without which it would not be possible even to speak of scientific results", Heisenberg (1952), p. 45. The same idea is expressed in Heisenberg (1930), pp. $1-4,11,62-4$ and passim, where it is supposed that the descriptive categories of classical physics are identical with those of everyday language; also in PP, pp. 44, 144; PB, pp. 64, 130. See also QMO, chap. iv.

19. For a recent exposition of this viewpoint, see Feyerabend (1965).

20 The analysis of the subject-object cut especially in acts of observation, leads to an epistemology that permits the displacement of the $\mathrm{S}-0$ cut so that the measuring instrument becomes functionally part of the observing subject. Observational languages then are context-dependent: where the context of observation depends on the location of the S-O cut. See Heelan (1972).

21 A. Einstein, "Physics and Reality", (1936) reprinted in Einstein (1950); and "Autobiographical Notes", Einstein (1949), pp. 20-21, 48 -9.

22. Sellars (1963).

23. Heisenberg (1958a), p. 29.

24. Ibid., p. 40.

25. PP, p. 173.

26. PP, p. 144.

27. AF, chaps. xiii and xvi; PB, chaps. vii and xvii.

28. For Heisenberg, the mathematical structure of a physical theory tells how nature really is: this he learned from Einstein. However, there is a problem: language is tied to everyday experience, since it is the product of conventions and historical processes. At first (1925-6), Heisenberg tried to force on the language of physics a semantical reinterpretation to make it conform to the quantum mechanical formalism; but Bohr convinced him (early 1927) that language need not be so re-interpreted; its old usages could be retained provided it was understood that the meaning of the old terms was sufficiently vague and imprecise. Besides language (or words), there were intuitions or pictures, roughly intuitive classical models; language uses these pictures realistically, of the macroscopic everyday world, but in quantum mechanics, a variety of complementary pictures is used to adapt ordinary language to the purposes of scientific expression; the reality expressed, however, is isomorphic, not with the picture or the language, but with the mathematical schemes, (or meaning); cf. Heisenberg (1930), p. 11, and notes 44, 61, 65 and 68 below.

29. AF, p. 14.

30 Heisenberg emphatically believes that physics, though necessarily expressed in terms of mathematical structures, depends in an important way on physical intuitions into possible experiments. He criticizes Born, Wightman, Symanski and others for being too mathematically oriented. "First solve the physics", he says echoing Bohr, "and then find the mathematical tools". (AHQP, 22 February 1963). "Such terms as 'the stability of the atom' or 'the quantum condition' give a different style to physics ... more difficult ; forgetting about mathematical schemes, one comes to a kind of substance of things which one is inclined to forget if one works in the mathematics alone ... [However] it is difficult to describe physics without having the logical connection [of mathematics]. Still by doing

Postprint: "Heisenberg and Radical Theoretic Change," Zeitschrift für allgemeine Wissenschaftstheorie, 6 (1975), 113-138. 
so, one is forced to think very carefully about what will happen in ... experiments". (AHQP, 28 February 1965).

31 Heisenberg reports that Einstein held that the valid applicability of the old physics is a necessary condition for the observation of facts in the new physics; PB, pp. 63-4.

32: AHQP, 17 February 1963: Heisenberg said, "Quantum theory ... certainly includes Newtonian physics in some way ... The concepts for quantum mechanics can only be explained by already knowing the Newtonian concepts; ... I would say that Newtonian mechanics is a kind of a priori for quantum theory ... in that sense that it is that language which enables us to say what we observe. If we have not the language of classical physics, I don't know how we should speak about our experiences" (italics inserted). See note 18 for other references.

33 Nevertheless, Heisenberg says that $\mathrm{L}_{\mathrm{N}}$ is the "product of the historical process" (AHQP, 17 February, 1963). Such a comment reveals, I believe, the Neo-Kantian influence on Heisenberg's thinking. This would have come from Hermann Weyl, Einstein and the contemporary academic milieu in Germany. Kuhn forces some of the conflicting elements in Heisenberg's thinking into the open in interviews of 17 and 28 February, 1963, AHQP.

34. Heisenberg's belief in the unrevisable cumulative character of scientific knowledge is expressed in his notion of closed theory or abgeschlossene Theorie. For an explicit analysis of this notion, see his "Recent Changes in the Foundation of Exact Science", (1934) in Heisenberg (1958a), pp. 11-26; "The Notion of 'Closed Theory' in Modern Science" (1948), in AF, pp. 39-46. This notion is adumbrated in Zeit. f. Physik, xviii (1927), p. 172.

34a. Though Einstein seemingly did not subscribe to this principle at the time of the discovery of special relativity, it does express what he later came to hold. In the Physicist's Conception of Nature (1958b), he writes that a closed theory "is valid for the entire cosmos and cannot be changed or improved" (pp. 27-8). Closed theories are unrevisable because, as he says, they are "idealizations" of reality (AF, pp. 184-191.) The evolution of physics, for Heisenberg, takes place through the dialectic of "idealization" (or formalization making a "closed theory") and research into "domains of applicability" of theories that are "closed". The domain of a closed theory is always to some extent indefinite. New research discovers areas of inapplicability of the old theory; this necessitates a new "idealization" (subject to principles of growth and continuity) and so on; see Heisenberg (1930), pp. 1-4. About the domain of applicability of a closed theory, he says, "When you axiomatize a theory, as for instance, Newton [did] ... then from this moment on you do not know whether this whole scheme has anything at all to do with nature because then it is closed. You may be lucky and it may actually fit to nature in a very large number of observations: all right, but you never can say how much it fits. I mean in some way, you have lost contact with nature". (AHQP, 5 July, 1963).

35. As Heisenberg wrote to W. Pauli on 24 June, 1925, "Grundsatz ist bei der Berechnung von irgenwelchen Grossen, wie Energie, Frequenz, usw., durfen wir nur Beziehungen zwischen prinzipiell beobachtbaren Grossen vorkommen", cited in Heisenberg,"Erinnerungen" (Heisenberg 1960); see also QMO, pp. 30—2 and passim.

36. As the author did in QMO.

37. Evidence for this, for example, is found in Physical Principles (Heisenberg 1930), pp. 1,65 .

38. PB, chap. v, "Quantum Mechanics and a Talk with Einstein (1925-6)", pp. 58-69.

39 PB, p. 63. Einstein had by that time come to reject vehemently the spirit of positivism in science; see. "Autobiographical Notes" (Einstein 1949), p. 49.

40. In practice then, Heisenberg's Principle of Observability functioned negatively, much like falsification in Karl Popper's philosophy of science; cf. Popper (1959; 1963; 
1972);

41. This point has been made by Popper, S. Toulmin, R. N. Hanson, P. Feyerabend and others.

42 Heisenberg's later explicit rejection of positivism, empiricism and pragmatism is contained in PB, "Positivism, Metaphysics and Religion (1952)," pp. 205-17 and "Atomic Physics and Pragmatism (1929)", pp. 93-102.

43. AF, p. 2; see also p. 161, "If this statement [that the Lorentz transformation tells the structure of space and time] is correct, the words 'space' and 'time' mean something other than they do in Newtonian physics".

44 AHQP, 5 July 1963: Heisenberg narrated how late in 1926 as he ran in Faelled Park near Bohr's Institute in Copenhagen, the insight came to him, "Why not simply say that only those things occur in nature which fit our mathematical scheme!" This thought, clearly inspired by Einstein, led him to consider the gamma-ray microscope, etc. The problem of expressing in language what occurred in nature as revealed by quantum mechanics was a real one: on the one hand, Bohr held that language was a given, consecrated by historical process, convention, everyday usage and the "customary forms of perception"; on the other hand, Heisenberg believed that the experience of relativity showed the flexibility of language to contextual re-interpretation forced by changes in the mathematical formalism. Heisenberg eventually came to accept the view (Bohr's) that it was not necessary to re-interpret the language of physics (classical language), but that the old language could remain provided limitations were imposed on its use in quantum mechanics, principally a certain vagueness of meaning; cf. note 68 .

45. As I have shown in QMO, chap. ii, Heisenberg's original intention was to reinterpret the kinematical variables within the context of the measuring process. The title of his revolutionary paper proclaims this intention, "Uber quantentheoretische Umdeutung kinematischer und mechanischer Beziehungen", ("On quantum theoretical reinterpretation of kinematic and mechanical relations"), Zeit. f. Physik, 33 (1925), pp. 879-893. Bohr was more cautious, as we have seen (note 44). Heisenberg came to accept complementarity in March 1927, as he told Kuhn (AHQP, 25 February 1963). Heisenberg's explicit adoption of Bohr's philosophy is announced in the Preface to his Physical Principles (Heisenberg 1930), but internal evidence in the text shows a considerable difference of viewpoint; cf. QMO, chaps. ii and iii. See below, especially note 68, for further comments on the differences between Bohr and Heisenberg.

46. Radnitzky (1972; 1973; 1974a; 1974b).

47. In PB, Heisenberg speaks of the goals of science: "Understanding' in Modern Physics (1920-22)", pp. 27-42, "Atomic Physics and Pragmatism (1929)", pp. 93102, "Positivism, Metaphysics and Religion (1952)", pp. 205-17. Predictive ability, he says, is not enough, because even Ptolemy could achieve this (pp. 31, 212). Exact science moves towards more and more comprehensive theoretical syntheses, expressed by simple mathematical formulae (p. 99). The beauty and simplicity of these formulae witness to their truth as expressing the real course of nature (p. 212; also AF, p. 172).

48 See for example, Heisenberg's Physical Principles (Heisenberg (1930), pp. 66, 105, 107; Philosophic Problems (Heisenberg 1958a), p. 24, where pragmatic continuity is implied. In noting the variety of formalisms developed for the quantum theory - by Schrödinger, Dirac and himself - and the variety of interpretations of the formalisms by Bohr, Schrödinger, Born and himself - he consoles himself with the thought that, after all, they all give pragmatically the same experimental results; cf., PB, p. 77. In AF, he writes, that the success and fruitfulness of a new theory is reason why scientists come to accept it; this he calls a "pragmatic criterion of value" (p. 163).

49 AHQP, 27 February 1963: Heisenberg said, "when you have a number of axioms as Newton had in ... Principia Mathematica, then the words are not only defined by the

Postprint: "Heisenberg and Radical Theoretic Change," Zeitschrift für allgemeine Wissenschaftstheorie, 6 (1975), 113-138. 
customary use of the language, but they are defined by their connections ... That is, you cannot change one word without ruining the whole thing". (italics inserted).

50. AF, pp. 187, 189. Enough has been said to prove that for Einstein and Heisenberg the mathematical formulae contained the relationships essential to a scientific understanding of phenomena. Both demanded model continuity as one passed beyond the domain of applicability of a Closed Theory to the more extended domain of the new theory. It does not follow, of course, that model continuity was in fact achieved; in the case of quantum mechanics, it was not achieved as Bohr and Heisenberg knew well. It is not always the case that $\mathrm{h}-.0$ and/or masses or quantum numbers become very large, that the classical formula is obtained. Cf. QMO, pp. 114-5. The same point is made in. Feyerabend (1970), pp. 296-300.

51. For example, Heisenberg (1930), pp. 37-8, 83, 89, 101, 116 where continuity of formalism is used as a criterion, or is affirmed.

52. Model Continuity and Contextual Re-interpretation result in the kind of problem about meaning-invariance in theory-change that Feyerabend (1965) articulates. The author has given his analysis of the conditions of continuity in development and change in Heelan (1972) and Heelan (1971)

53 Einstein (1949), pp. 23-63.

54. PB, p. 68, AF, pp. 172, 174-5.

55 The extent and consequences of the use by Heisenberg of these research-guiding principles in the construction of quantum mechanics, will be considered in another paper.

56. AF, op. cit.

56. AF, chap. 12, "Changes of Thought Patterns in the Progress of Science", pp. 15465. The citations are on pp. 163--5. This paper was given during the student unrest of the late '60's and perhaps its rhetorical form was influenced by Heisenberg's rejection of what he took to be the use of political means to transform the disciplines. He does admit, however, that there are social components to a scientific revolution, for, as he says, echoing Wolfflin, not everything is possible in every epoch (p. 158).

58 Nevertheless, Heisenberg said that he is in agreement with Kuhn's theory of scientific revolutions. He notes that our inquiries are endless, our theories are subject to being overturned, and that mystical and religious criteria may sometimes be operative in scientific change; for the last-mentioned, he cites the views of Pauli and Kepler. "There is no solid bottom ... one can never hope that these fundamentals (reached at any time) will rest forever", he asserts (AHQP, 17 Feb., 1963).

59. Theory-monism is a research-guiding principle that advocates staying within the paradigm of tested contemporary research: theory-pluralism, on the other hand, advocates the construction of a variety of different paradigms which are then tested against one another. The principle advocates of theory-pluralism today are Popper and Feyerabend. For an excellent review of the problems and its literature, see Radnitzky (1974b).

60. AF, p. 189. The theory of elementary particles that will unify the existing domains of physics will be a Closed Theory, but it will not close physics; this must grow in the direction of biology and other disciplines, where new concepts, such as life, appear that do not appear in physics.

61 The method used can be compared with Husserlian eidetic intuition into the sense of a given (in this case of the givenness of scientific observables) : one aims, by a type of eidetic phenomenological reduction, at the intuitive essence of what the theory says (should or could say) about the World; see Heelan (1972). For eidetic phenomenological reduction, see Husserl (1952); also Husserl (1931).

62. Heisenberg's interesting account of the debate between himself and Bohr on one side and Schrödinger on the other is found in PB, pp. 70-76. Schrödinger said of quantum mechanics that it was, "von abschreckender ja abstossender Unanschaulichkeit

Postprint: "Heisenberg and Radical Theoretic Change," Zeitschrift für allgemeine Wissenschaftstheorie, 6 (1975), 113-138. 
and Abstraktheit" (quoted by Heisenberg in Zeit.f. Physik, xliii, 1927, p. 195, note).

63. He did not follow out the logic of his principle, however, to determine how such a re-interpretation would affect the sense of classical physics; and subsequent events, particularly his acceptance of complementarity, aborted such an inquiry.

64. About Heisenberg's disagreements with Bohr, see PB, pp. 76-81, and AHQP, 11, 13, 15, 19, 25 and 27 February and 5 July 1963. About Bohr, Heisenberg said, "I have really in this whole period (1925-27) been in real disagreement with Bohr and the most serious disagreement was at the time of the Uncertainty Relations", (15 February 1963). Bohr wanted to start with "intuitions of how nature was and worked", he asserted,. "Bohr was not a mathematically-minded man ... he was Faraday but not Maxwell". Bohr insisted on the experimental inadequacies of matrix mechanics; Heisenberg was less worried about these, trusting in the consistency of the mathematical formalism (25 February 1963). Bohr wanted to use both wave and particle pictures jointly to give intuitive sense of how nature is and works; Heisenberg wanted to use the mathematical formalism as guide to what nature is really like (27 February 1963, cf. also note 68).

65. About Bohr's philosophy, see Petersen (1968); QMO, pp. 44-56; Heelan (1970a), particularly, pp. 108-9. Bohr's philosophy has been described both by Heisenberg and Petersen as a preoccupation with the possibilities of unambiguous communication through language. Bohr saw quantum mechanics as revealing certain limitations on the possibilities of human discourse arising out of (i) the inseparability of objective content and the observing subject and (ii) the fact that the partition between the actor and the audience can be moved at will so that what was part of the audience becomes in a new context part of what is being observed on the stage. The reason, he says is the "coupling between the phenomena and the agency by which it is observed". This condition "forces us to adopt a new method of description designated as complementary in the sense that any given application of classical concepts precludes the simultaneous use of the classical concepts which in a different connection are equally necessary for the elucidation of the phenomena", Bohr (1934), pp. 10-11. Bohr held that all communicable knowledge about the world is necessarily expressed in terms of the "customary forms of perception" of which the categories of classical physics are a clear and precise expression; see ibid., pp. 1, 5, 15-9, 22, 90-3, 103, 111; and "Discussions with Einstein on Epistemological Problems in Atomic Theory", in Albert Einstein: Philosopher-Scientist (Einstein 1949), p. 209. As was pointed out above (note 28), Heisenberg uses the distinction between language, picture, and mathematical scheme (or meaning) in describing Bohr's philosophy, "Bohr was from his youth interested in our ways of expression, the limitations of word, the problem of talking about things where one knows that the words do not really get hold of the things... Bohr tried to keep the picture while at the same time omitting classical mechanics. He tried to keep the words and the pictures without keeping the meaning of the words and pictures", So what do you do? he asks. He rejects Sommerfeld's "escape into mathematics" and endorses Bohr's perception that there was a philosophical problem to solve (AHQP, 11 February 1963).

66. In the preface to Heisenberg (1930), Heisenberg identifies himself with the Kopenhagener Geist der Quantentheorie. Later (in 1955), he wrote "What was born in Copenhagen in 1927 was not only an unambiguous prescription for the interpretation of experiments, but also a language in which one spoke about Nature on the atomic scale and in so far a part of philosophy", p. 16 in Heisenberg (1955).

67. To judge by the unending stream of argument and counterargument about the meaning and significance of complementarity during the past forty years, we are forced to conclude that complementary was no solution, or at least, not a clear and convincing solution to the many physicists, philosophers and logicians that have since tried to master quantum mechanical theory.

Postprint: "Heisenberg and Radical Theoretic Change," Zeitschrift für allgemeine Wissenschaftstheorie, 6 (1975), 113-138. 
68. AHQP, Heisenberg said that at the time he wrote the paper on the Uncertainty Relations, he did not realize that the words "position", etc. could still be used in the old sense, but with limitations: Bohr made him realize this a few months later (27 February 1963). In fact, referring to his original intention, he said that he learnt from Bohr that "the thing I in some way attempted could not be done ... one has to talk about, e.g., the diffraction pattern (as a wave phenomenon) while holding the indivisible character of the electron (as a particle phenomenon) ... [for this] one needs a language... taken from the historical process [which in our case] is a classical language $\left[\mathrm{L}_{\mathrm{N}}\right]$... thus one cannot avoid the tension between classical precise language and its limits (17 February 1963). Nevertheless, the experience of relativity showed that his original intention was viable. Comparing the quantum mechanical and the relativistic revolutions: in relativity, he said, actual language has adjusted to the mathematical scheme... In quantum theory, language has never adjusted to it... The mathematicians have shown that it could adjust to it by changing the Aristotelian logic... So far nobody has been willing to pay that price. Now that was not clear at that time. But still it was clear that probably the only sensible thing to do was to use the old words and always remember their limitations" (27 February 1963). Various non-Aristotelian logics have been proposed, starting with the paper of G. Birkhoff and J. von Neumann, "The Logic of Quantum Mechanics", Ann. of Math., 37 (1961), pp. 155-184; of Heelan (1970b).

69 The relative invisibility of eidetic methods in modern physics arises from the fact that there seems to be no systematic place for it or for the kind of evidence it produces in the "received" views, both empiricist and rationalist, of scientific inquiry. Some results in elementary particle physics, as, e.g., those reported in Gavroglu (1973) were produced by the use of eidetic methods, according to a verbal report given to the author by Gavroglu.

70 For Heisenberg's work on unified field theory, see for example, Heisenberg (1963; 1966).

71 AF, p. 164.

72. Ibid.

\section{REFERENCES}

Bohr, N. 1934. Atomic Theory and the Description of Nature (Cambridge Univ. Press, London).

Einstein, A. 1905. "On the Electrodynamics of Moving Bodies" Annalen der Physik xvii (1905), translated and reprinted in The Principle of Relativity, op. cit., pp. 37--85.

Einstein, A. 1949. "Autobiographical Notes," in Einstein: Philosopher-Scientist, ed. by P. Schilpp (Library of Living Philosophers, Edmonton, Ill.), pp. 53-63.

Einstein, A. 1950. Out of My Later Years (New York, Philosophical Library) pp. 59—97;

Feyerabend, P. 1965. "Problems of Empiricism, I", pp. 145-260, in Colodny, R. (ed.) Beyond the Edge of Certainty (Pittsburgh, Pittsburgh Univ. Press),

Feyerabend, P. 1970. "Problems of Empiricism II", pp. 275-355 in Colodny, R. (ed.), Nature and Function of Scientific Theories (Pittsburgh, Univ. of Pittsburgh Press),.

Gavroglu, Costa, 1973. "Semiweak interactions and the non-leptonic weak decays", Nuevo Cimento 16A (1973), p. 61.

Heelan, P.A. 1965. Quantum Mechanics and Objectivity: A Study of the Physical Philosophy of Werner Heisenberg (The Hague, Nijhoff).

Heelan, P.A. 1967. "Horizon, Objectivity and Reality in the Physical Sciences", Internat. Philos. Qrtly, 7 (1967), pp. 375-412.

Heelan, P.A. 1970a. "Complementarity, Context-dependence and Quantum Logic", Foundations of Physics 1 (1970), pp. 95-110.

Heelan,P.A. 1970b. "Classical Logic and Quantum Logic: Their Respective

Postprint: "Heisenberg and Radical Theoretic Change," Zeitschrift für allgemeine Wissenschaftstheorie, 6 (1975), 113-138. 
Roles", Synthese, 21 (1970), pp. 2-33.

Heelan, P. 1971."Logic of Framework Transpositions," Internat. Philos. Qrtly, xi (1971) p. 314-34.

Heelan, P.A. 1972. "Hermeneutics of Experimental Science in the Context of the LifeWorld", Philosophia Mathematica, (1972), pp. 101-44 and the commentary by T. Kisiel

Heisenberg, W. 1925. "Uber quantentheoretische Umdeutung kinematischer und mechanischer Beziehungen", ("On quantum theoretical re-interpretation of kinematic and mechanical relations"), Zeit. f. Physik, 33 (1925), pp. 879-893.

Heisenberg, W. 1930. Physical Principles of the Quantum Theory (University of Chicago Press).

Heisenberg, W. 1955 "The Development of the Interpretation of Physics", in Niels Bohr and the Development of Physies, ed. by W. Pauli (New York, McGraw-Hill), pp. $12-29$.

Heisenberg, W. 1958. Physics and Philosophy (New York, Harper and Row, World Perspectives Series, vol. 19) - referred to in text as PP.

Heisenberg, W. 1958a. Philosophic Problems of Nuclear Science (London, Faber and Faber).

Heisenberg, W. 1958b. Physicist's Conception of Nature (London, Hutchinson)

Heisenberg, W. 1960 "Erinnerungen an die Zeit der Entwicklung der Quantum Mechanik", in Theoretical Physics in the Twentieth Century: Memorial Volume to Wolfgang Pauli, ed. by M. Fierz and J. F. Weisskopf (New York, Interscience), pp.40-7.

Heisenberg, W. 1963. "Entwicklung der einheitlichen Feldtheorie der Elementarteilchen", Naturwissen., 50 (1963), pp. 3-7.

Heisenberg, W. 1966. Unified Theory of Elementary Particles (London, Interscience, 1966).

Heisenberg, W. 1971. Physics and Beyond, (Harper and Row, World Perspectives Series, vol. 42) -- referred to in text as PB.

Heisenberg, W. 1974. Across the Frontiers, trans., from the German by Peter Heath (Harper \& Row) -referred to in text as AF.

Husserl, E. 1952, Ideen $z u$ einer reinen Phanomenologie and phanomenologischen Philosophec, I, II and III. Husserliana, vols. I, III, IV and V (The Hague, Nijhoff).

Husserl (1931) Ideas., trans.of Vol. 1 by W. R. Boyce Gibson (London, Allen and Unwin).

Kisiel, T. and G. Johnson, "New Philosophies of Science in the USA: Selective Survey", Zeit. f. Allgemeine Wissenschaftstheorie, 5 (1974), pp. 138-191.

Kuhn, T.S. 1962. Structure of Scientific Revolutions (Chicago, Univ. Press)

Lakatos, I. 1967. "History of Science and its rational reconstruction", pp. 91-136, in M. Wartofsky and R. S. Cohen (eds.) Boston Studies in the Philosophy of Science, vol. 3, (New York, Humanities Press).

Lakatos I. and Musgrave, 1970. A. Criticism and Growth of Knowledge (Cambridge Univ. Press, London);

London F. \& Bauer, E. 1939. La théorie de !'observation dans la physique quantique (Paris, Hermann),

Lorentz, H.A. 1904. "Electromagnetic Phenomena in a System Moving with any Velocity less than that of Light", Proc. Acad. Sci. Amsterdam, vi (1904), reprinted is The Principle of Relativity by H. A. Lorentz, A. Einstein, H. Minkowski and H. Weyl (Dover, New York), pp.10-36.

Petersen, A. 1968. Quantum Physics and the Philosophical Tradition (M.I.T. Press, Postprint: "Heisenberg and Radical Theoretic Change," Zeitschrift für allgemeine Wissenschaftstheorie, 6 (1975), $113-138$. 
Camb. Mass.) :

Popper, K. 1959. The Logic of Scientific Discovery (London, Hutchinson).

Popper, K.1963. Conjectures and Refutations (London, Routledge and Kegan Paul).

Popper, K. 1972. Objective Knowledge (London, Oxford Univ. Press)

Radnitzky, G 1972. "Towards a 'Praxiological' Theory of Research," Systematics, x (1972), pp. 129-185.

Radnitzky, G 1973. "Philosophy of Science in a New Key," Methodology and Science, vi (1973), pp. 134-178.

Radnitzky, G. 1974a. "Philosophie de la recherche scientifique," Archives de Philosopie, 37 (1974), pp. 5-76.

Radnitzky, G 1974b. Preconceptions in Research (London, Human Context Books, 1974).

Sachs, M. 1968. "The Elementarity of Measurement in Relativity" in Boston Studies in the Philosophy of Science, Vol. iii, ed. by R. S. Cohen and M. Wartofsky (New York, Humanities Press), pp. 56-80.

Sellars, W. 1963. "Philosophy and the Scientific Image", pp. 1-40 in Science, Perception and Reality (London, Routledge and Kegan Paul).

Strauss, M. 1968. "Einstein's Theories and the Critics of Newton", Synthese, 18 (1968), 251-84.

Suppe, F.(ed.). 1974.. The Structure of Scientific Theories, (Urbana, Ill., University of Illinois Press).

Wigner, E. 1954. Progr. Theor. Phys., 2 (1954), p. 437.

Wigner, E. 1962. "Remarks on the Mind-Body Problem", in The Scientist Speculates, ed. by I. J. Good (London: Heineman), pp. 284-301.

Wigner, E. 1967. Symmetries and Reflections (Bloomington: Univ. of Indiana Press), p. 45. 


\author{
Comments to Heelan's Thesis \\ by \\ WERNER HEISENBERG
}

I think I can agree with most of your statements, but I would like to make one exception concerning the difference of opinions between Bohr and myself. I think that you overemphasize these differences, and I might mention in this connection a few passages of your paper. You say that "I attributed descriptive force to the newly interpreted variables while Bohr chose to speak of wave and particle "pictures" which were not in his view true models of atomic phenomena". But I am sure that Bohr would have agreed if one would say that he attributed descriptive force to the pictures he used; but he would perhaps have added that he did not know what the word 'true' means, when you speak about true models of the atomic phenomena. With respect to the "blurring the distinction between signifier and signified" I may remind you of my discussions with Bohr on the problem whether the cut between that part of the experiment which should be described in classical terms and the other quantum theoretical part had a well defined position or not. I argued that a cut could be moved around to some extent while Bohr preferred to think that the position is uniquely defined in every experiment. For instance the water droplets in a cloud chamber could either be considered as the "signifier" for the motion of the electron or as being "signified" by the black lines on the photographic plate. Bohr and I sometimes disagreed when we tried to approach to the same goal (namely the interpretation of quantum theory) from different directions. But finally I did not see any important difference between the principle of complementarity and the reinterpretation of classical variables after I had understood that the relations of uncertainty are just a special case of complementarity. Perhaps you should formulate more clearly what you mean by such terms as "true models of atomic phenomena".

With respect to the quotations (in the footnotes), I am not sure whether the transcription of the tapes is always quite correct. But it may also be that I have occasionally been too careless in formulating what I meant.

Adresse des Autors:

Prof. Dr. Werner Heisenberg, Max-Planck-Institut für Physik and Astrophysik, 8 München 40, Fohringer Ring 6

Zeitsdsrift fur allgemeine Wissenachaftatheorie VlIl (1975)

(C) Franz Steiner Verlag GmbH, Wiesbaden, BRD

Postprint: "Heisenberg and Radical Theoretic Change," Zeitschrift für allgemeine Wissenschaftstheorie, 6 (1975), 113-138. 


\author{
Reply \\ of
}

\title{
PATRICK A. HEELAN
}

No model of atomic phenomena is of itself either true or false, only statements purporting to use the model to state what is the case are capable of being true or false. Statements are true, if they make the correct semantical use of the model and if they state what is in fact the case. Two kinds of models occur in the interpretation of quantum mechanics : one which Heisenberg preferred, constituted by the (non-classical) mathematical formalism of quantum mechanics, and the other, which Bohr preferred, constituted by the (classical) wave and particle 'pictures' of complementarity. If true statements can be made by the use of both models, then clearly different semantical usages are involved. Bohr could make true statements and Heisenberg also : they approached the same goal (a true interpretation of quantum theory) from different directions. But this does not imply that Bohr and Heisenberg are using their respective models in the same way. I would hold, for example, that Heisenberg used the mathematical model literally of atomic phemomena, while Bohr used the wave and particle 'pictures' metaphorically of the same phenomena. Heisenberg's usage, I believe, was the more scientific, because, unlike metaphorical usage, it implied nothing that was hidden and oblique. By a 'true model of atomic phenomena', then, I mean ,one that, when correctly used, is used in a literal, as opposed to a metaphorical manner. By that, I do not mean to imply that there is no truth in metaphor, or less truth, but that in science, truth aims at non-metaphorical expression. Thus, Bohr and Heisenberg could both be right, but not right in the same way, since they used different models and hence different semantical rules to reach the goal of true expression. The route Heisenberg took, however, was in my opinion both more illuminating from a philosophical point of view, and more scientific in what it foreshadowed about the future development of physics.

I thank Professor Heisenberg for forcing me to clarify my terms and for his comments on my paper.

\footnotetext{
Zeitsthrift fur allgemeine Wissenachaftstheorie VI/I (1975)

(C) Franz Steiner Verlag GmbH, Wiesbaden, BRD
} 